\title{
Jogo de damas: trajetórias de mulheres nas ciências sociais paulistas (1934-1969)*
}

\author{
Dimitri Pinheiro**
}

\begin{abstract}
Resumo
O artigo examina o processo de institucionalização das ciências sociais em São Paulo privilegiando o entrelaçamento entre disputas acadêmicas e assimetrias de gênero. O fio condutor é a reconstituição das trajetórias de quatro professoras da primeira geração de intelectuais universitários entre 1934 e 69: Gilda de Mello e Souza, Gioconda Mussolini, Maria Isaura Pereira de Queiroz e Paula Beiguelman. Apesar da maior inserção profissional das mulheres nas novas instituições de ensino superior, a progressão de suas carreiras foi tortuosa e difícil. Sob a lógica patriarcal do regime de cátedras, elas estiveram em desvantagem, ocupando geralmente posições inferiores e de maior insegurança na hierarquia acadêmica.
\end{abstract}

Palavras-chave: Gênero, Trajetória, Academia, Cátedra, Assimetria.

\footnotetext{
* Recebido para publicação em 15 de julho de 2014, aceito em 22 de outubro de 2015. Este texto é em parte resultado da dissertação de mestrado defendida junto ao Programa de Pós-Graduação em Sociologia da USP sob orientação do professor Dr. Luiz Carlos Jackson. Agradeço também a Irene Cardoso, Heloísa Pontes e Renata Guedes Mourão Macedo pelas críticas e sugestões que ajudaram a aperfeiçoá-lo. A realização da pesquisa contou com auxílio da Fapesp.

*** Doutor pelo Programa de Pós-graduação em Sociologia, Universidade de São Paulo (USP), São Paulo, SP, Brasil. dimitri.pinheiro@usp.br 
Ladies' Game: Women Trajectories in São Paulo Social Sciences (1934-1969)

\begin{abstract}
The article investigates the institutionalization of social sciences in São Paulo with a focus on the interlinking of academic disputes and gender asymmetries. The connective thread is our reconstruction of the trajectories of four professors of the first generation of university intellectuals between 1934 and 1969: Gilda de Mello e Souza, Gioconda Mussolini, Maria Isaura Pereira de Queiroz, and Paula Beiguelman. In spite of an increase in women professionals' entry into the new higher educational institutions, progression in their careers was hard and tortuous. Under the paternalistic logic of the cathedra institutional structure, they were at a disadvantage, generally occupying lower and more insecure positions in the academic hierarchy.
\end{abstract}

Key Words: Gender, Trajectory, Career, Intellectual, Asymmetry. 
Os obstáculos ainda são imensamente grandes - e muito difíceis de definir. De fora, existe coisa mais simples do que escrever livros? De fora, quais os obstáculos para uma mulher, e não para um homem? Por dentro, penso eu, a questão é muito diferente; ela ainda tem muitos fantasmas a combater, muitos preconceitos a vencer. $\mathrm{Na}$ verdade, penso eu, ainda vai levar muito tempo até que uma mulher possa se sentar e escrever um livro sem encontrar com um fantasma que precise matar, uma rocha que precise enfrentar. E se é assim na literatura, a profissão mais livre de todas para as mulheres, quem dirá nas novas profissões que agora vocês estão exercendo pela primeira vez?

(Woolf, 2013:17).

Não conservei ressentimento com respeito aos que se opunham à minha ascensão na Universidade. Excelentes pessoas, situavam-se dentro de seu tempo e do seu meio, expoentes de uma sociedade preconceituosa para com as mulheres. Não se suponha que tenha sido eu o único alvo da discriminação: esta visava à todas. No meu caso, a resistência provocou o desenrolar de todo o processo. Em outros, este se interrompeu ou nem foi acionado, dado o afastamento da interessada, seja voluntário, seja imposto pelas circunstâncias (Canabrava, 2005:34).

Não [fomos marginalizadas]. Tínhamos até bastante prestígio. É verdade que a relação conosco era ambivalente. Havia um interesse franco pelo nosso destino, mas uma disposição bem menor de se apostar nele. Creio que àquela altura os homens [...] se relacionavam conosco um pouco como um marchand diante de um artista jovem que, embora aparentando talento, ainda está muito no início da carreira para merecer crédito (Mello e Souza, 1981$4: 147-148)$.

Em 1954, Florestan Fernandes assumiu interinamente a chefia da Cadeira de Sociologia I da Faculdade de Filosofia, Ciências e Letras (FFCL) da Universidade de São Paulo (USP), em substituição a Roger Bastide que voltara definitivamente para a 
168 Jogo de damas: trajetórias de mulheres nas ciências sociais paulistas

França. O novo regente iniciou, então, uma reformulação das atividades, constituindo um programa de pesquisas centrado na questão racial e progressivamente direcionado ao problema do desenvolvimento. A mudança se refletiria na recomposição dos membros da cadeira: Fernando Henrique Cardoso sendo designado para o cargo de primeiro assistente e Renato Jardim Moreira segundo assistente. Considerando que um e outro eram os auxiliares de ensino mais novos da cadeira, que Maria Isaura Pereira de Queiroz era auxiliar de ensino mais antiga e Gilda de Mello e Souza (1919-2005) primeira assistente, a decisão significou um "ato de força", ao mesmo tempo afirmativo da autoridade temporal e subversivo da hierarquia "natural" da carreira docente. Ato de força exercido em favor dos auxiliares associados ao novo projeto acadêmico - ambos haviam colaborado na pesquisa sobre relações raciais encomendada pela revista Anhembi e patrocinada pela Unesco, além de já estarem realizando seus trabalhos sob essa orientação -, e em prejuízo das assistentes, alinhadas ao projeto de sociologia da cultura estabelecido pelo mestre francês. ${ }^{1}$

$\mathrm{O}$ episódio ilumina o entrelaçamento entre disputas acadêmicas e assimetrias de gênero no contexto das novas instituições de ensino superior paulistas. Como se sabe, o elevado contingente feminino foi um traço distintivo da clientela dos cursos de ciências sociais oferecidos na Escola Livre de Sociologia e Política (ELSP) e FFCL-USP. Entre 1936 e 1955, as mulheres constituíam, respectivamente, 39\% e 57\% dos diplomados em cada um desses cursos. $^{2}$ Nas escolas tradicionais como medicina $e$

1 Fernando Henrique oferece respaldo a essa apreciação: "Ele [Florestan] já tinha feito uma violência quando o Roger Bastide foi embora: eu era auxiliar de ensino [...]. Naquele tempo a hierarquia era essa: auxiliar de ensino, segundo assistente, primeiro assistente. E o Florestan me nomeou primeiro assistente dele, naturalmente criando dificuldades com todos os demais colegas" (Romão, 2006:114; ênfases adicionais). Como se vê, as "dificuldades" foram criadas com as colegas, que, até aquele momento, ocupavam posição hierarquicamente superior.

2 Um levantamento restrito à $\mathrm{FFCL}$, mas abrangendo intervalo maior de tempo (1936-1969), contabilizou uma proporção mais elevada de mulheres entre os diplomados: 65\% (Spirandelli, 2011:41). 
direito - para onde afluíam os herdeiros da classe dirigente - essa proporção não superava o patamar de 8,5\% (Miceli, 2001:94-96). A vantagem da FFCL sobre a ELSP deve ser atribuída ao comissionamento, recurso que visava solucionar a crise provocada pela carência de alunos e mediante o qual professores primários eram, mantidos seus honorários, dispensados das funções para realizar um curso superior (Limongi, 2001:188). Conforme foi se convertendo em arranjo rotineiramente empregado para driblar a escassez de recursos necessários à contratação de docentes $e$ funcionários administrativos (Ferreira, 1988:24), esse mecanismo também constituiria uma das vias típicas de inserção profissional aberta às mulheres.

Não obstante o formidável contingente $e$ as chances de inserção profissional que a FFCL ofereceu às mulheres, a progressão de suas carreiras, quando comparada à dos homens, foi tortuosa e difícil. A conquista oficial da cátedra por mulheres até 1969 - ano em que a reforma universitária põe fim ao sistema - foi avis rara. Elas marcaram presença, todavia, como assistentes e auxiliares de ensino. Seguindo a lógica tradicional, o regime de cátedras alocava as mulheres em situação de desvantagem, associando-as às posições subalternas e de maior insegurança na hierarquia da carreira. Nessas posições, as possibilidades de progressão dependiam dos homens, que, com pouquíssimas exceções, ocupavam os cargos superiores. A socialização em um mundo patriarcal os levava a transferir as lógicas subjacentes a esse sistema de dominação para o interior de relações profissionais modernas, nas quais, ao menos em princípio, maior equilibrio era postulado. ${ }^{3}$

3 Exploro aqui a sugestão de Mariza Corrêa (1995:54): "Sistema hierárquico, o de cátedra era também patriarcal: se os titulares da cadeira [de antropologia] foram todos homens, as assistentes eram todas mulheres [...]". A caracterização também encontra paralelo sugestivo na dificuldade de inserção profissional dos judeus num sistema acadêmico marcadamente antissemita como o da Alemanha entre 1890 e 1918: "A dificuldade decorria do fato de que a promoção dos instrutores judeus tinha de ser recomendada por catedráticos não-judeus, e então os preconceitos se faziam presentes" (Ringer, 2000:135-136). 
As dificuldades objetivamente derivadas dessa situação encontravam contrapartida subjetiva nas próprias mulheres. Também socializadas segundo os mesmos padrões patriarcais $e$ tendo integrado as turmas inaugurais da FFCL, constituíram a primeira geração a obter uma formação acadêmica mais sólida $e$ reunir condições para redefinir o papel que tinham sido socialmente destinadas a desempenhar: "mães e donas de casa" (Pontes, 2007:100). No entanto, o desajustamento entre a educação para a vida doméstica $e$ as exigências postas pelo desenvolvimento da carreira intelectual num ambiente profissional dominado por homens, repercutia internamente às mulheres como um dilaceramento subjetivo que, desencadeando dúvidas, inseguranças e conflitos, amplificava internamente as pressões exercidas pelo julgamento dominante.

Assim, se, desde 1920, as transformações nas estruturas social e ocupacional ocorridas na cidade de São Paulo produziram mudanças sensiveis nas relações entre os gêneros - sobretudo nos extratos sociais mais favorecidos -, elas transcorreram de forma desigual e descontínua, reproduzindo parcialmente assimetrias pré-existentes. Desse modo, embora o deslocamento das "fronteiras sexuais" das profissões no âmbito do setor terciário em expansão tenha representado um progresso quanto aos requisitos de admissão, as lógicas patriarcais continuavam a reger o acesso às diferentes carreiras $e$, mais especificamente, a disputa por posições mais favoráveis dentro delas (Perrot, 2009:164).

Questionada sobre o impacto da FFCL na vida das mulheres de sua geração, Gilda identificou formas típicas de ajustamento que teriam variado em função da formação escolar, do ambiente familiar e do temperamento de cada uma delas. Para aquelas que, como ela mesma, tentaram "inventar para si um novo destino", haveria "três esquemas básicos": o abandono do modelo feminino tradicional em favor da plena realização profissional, com o sacrifício da dimensão afetiva; a opção parcial pela carreira preservando as obrigações familiares $e$ a realização afetiva, solução harmoniosa do ponto de vista humano, mas que se traduziria numa satisfação profissional incompleta; e o ajuste da 
tradicional dedicação à vida doméstica ao desempenho das tarefas de assistência intelectual, cuja realização se daria através do marido (Mello e Souza, 1981-4:149).

As trajetórias de Gioconda Mussolini (1913-1969), Paula Beiguelman (1926-2009), Maria Isaura e da própria Gilda - quatro das mais destacadas integrantes da primeira geração de universitários paulistas - podem ser compreendidas à luz desses esquemas interpretativos. Em alguma medida, a inserção profissional de cada uma delas esteve vinculada a diferentes cadeiras da FFCL (Antropologia, Política, Sociologia II e I respectivamente), o que permite considerar o impacto da institucionalização dessas especialidades na progressão de suas carreiras. Além disso, o percurso dessas cientistas sociais não deve perder de vista os trunfos acumulados pelos homens mais bemsucedidos na faculdade entre 1934 e 69: Antonio Candido de Mello e Souza e Florestan Fernandes especialmente. Cada um ao seu modo produziu um conjunto bibliográfico extenso $e$ qualificado (legitimados imediata e posteriormente pelas instâncias de consagração acadêmica); obteve reconhecimento pelo exercício do papel de professores e formadores; idealizou e liderou programas coletivos de pesquisa; deteve a posição mais elevada da hierarquia institucional; e alcançou projeção nas esferas mais amplas da política e da cultura. Tais realizações foram conjugadas aos papeis de esposo e pai, fato que chama atenção para a importância de fatores como aliança matrimonial e arranjo familiar nas conquistas pessoais. Veremos que nenhuma das mulheres cujos trajetos são examinados neste artigo conquistou sucesso em todas essas dimensões. ${ }^{4}$

\footnotetext{
${ }^{4}$ Por limitações relativas aos objetivos (a ênfase nas assimetrias de gênero) e ao caráter das fontes (predominantemente institucionais), bem como à economia interna da exposição, este artigo não se detém na análise do conteúdo dos trabalhos dessas autoras. A referência às obras se dá aqui predominantemente em chave temática. Na eventual necessidade de uma avaliação de conteúdo remeteremos, sempre que possível, a intérpretes dessas obras. Para evitar repetição me referirei às autoras apenas pelo primeiro nome.
} 


\section{1}

Gioconda nasceu em 1913 na cidade de São Paulo. Foi a terceira das sete filhas do casal formado pelo imigrante italiano Umberto Mussolini e a brasileira Adalgisa da Veiga. A julgar pelas escolas onde realizou os estudos primários - Grupo Escolar Regente Feijó e Escola Modelo do Brás - viveu a infância nas redondezas dos bairros operários da Luz ou Brás.

O currículo escolar rigidamente orientado não deixava muitas alternativas às jovens - principalmente aquelas com uma origem social desfavorável - além da progressão ao ensino normal $e$, a partir daí, à profissionalização como professoras do ensino primário. De fato, após cursar dois anos de ensino complementar e mais quatro referentes ao normal, Gioconda se formaria normalista em 1932. A habilitação lhe permitiu o acesso ao Instituto Caetano de Campos, onde realizou, dois anos depois, o curso de aperfeiçoamento para professores do ensino primário (correspondente aos dois primeiros anos do curso de pedagogia oferecido pela FFCL).

Concomitantemente, Gioconda ingressou na rede pública de ensino, sendo designada para lecionar no Grupo Escolar Pariquera-Açu, então localizado na zona rural de Jacupiranga (município do litoral sul do estado). Esse trabalho lhe propiciou o primeiro contato com o que posteriormente viria a ser um dos seus principais objetos de pesquisa: as comunidades caiçaras do litoral de São Paulo e Rio de Janeiro. A experiência, no entanto, seria interrompida em 1935, quando foi comissionada para cursar ciências sociais no grupo de professores primários recrutado por Fernando de Azevedo a fim de solucionar o problema da crise enfrentada pela FFCL nos primeiros anos de seu funcionamento.

Nesse mesmo ano, provavelmente indicada por algum de seus professores, Gioconda foi contratada como pesquisadora pela Seção de Documentação Histórica e Social do Departamento Municipal de Cultura, dirigido por Sérgio Milliet. A contratação pôs a jovem em contato com os intelectuais da ala cultural do Partido Democrático - além do próprio Milliet, Mário de Andrade, Paulo Duarte, entre outros - e permitiu que ela participasse de três 
pesquisas pioneiras dirigidas pelos professores estrangeiros contratados pela $\mathrm{ELSP}^{5}$, bem como da criação da Sociedade de Etnografia e Folclore em 1936. Desse modo, antes mesmo de se formar, a estudante já transitava pelas principais instituições que compunham o embrionário sistema cultural paulista. Tal experiência lhe proporcionaria precocemente

[...] um treinamento que se desdobra em teorias e práticas, [na] participação direta em investigações sociais de grande relevância [...], na aquisição de instrumentos metodológicos e [...] desenvolvimento da reflexão teórica necessária à formação de uma cientista social moderna (Ciacchi, 2007b:14).

Gioconda concluiu o curso em 1937 e no ano seguinte voltou a lecionar no ensino primário, agora no Grupo Escolar República do Paraguai, localizado no bairro Vila Prudente, em São Paulo. Porém, o trabalho foi logo interrompido por novo comissionamento junto à FFCL para trabalhar como auxiliar de ensino da Cadeira de Sociologia I, então chefiada por PaulArbousse Bastide. No entanto, a ela foram efetivamente atribuídos os seminários dos cursos ministrados por Roger Bastide na Cadeira de Sociologia II. ${ }^{6}$ Também integrou juntamente a outros auxiliares - como Lavínia da Costa Vilela e Mário Wagner Vieira

5 "O padrão de vida dos lixeiros de São Paulo" e "Assistência filantrópica na cidade de São Paulo", com Samuel Harman Lowrie e Bruno Rudolfer; e "O padrão de vida dos operários de São Paulo", com Horace Bancroft Davis - os resultados dessas investigações seriam publicados na Revista do Arquivo Municipal.

${ }^{6} \mathrm{O}$ anuário da faculdade especifica "Orientações de leitura", oferecido à turma do segundo ano de 1942; "Pesquisa sobre vizinhanças", dirigida em colaboração com Lucila Hermann às turmas do segundo e terceiro anos de 1943; e "Desordens mentais", voltado às turmas do segundo e terceiro anos de 1944 (USP, 1953:647-648). 
da Cunha - o Centro de Pesquisa e Documentação Social (vinculado às cadeiras de sociologia). ${ }^{7}$

Em 1941, Gioconda ingressou sob orientação do professor alemão Herbert Baldus no recém-criado Curso de Pós-Graduação da ELSP, que concluiria quatro anos depois com a dissertação "Os meios de defesa contra a moléstia e a morte em duas tribos brasileiras", publicada como artigo na Revista do Arquivo Municipal, em 1945. Essa passagem pela ELSP a aproximaria de outro professor alemão, Emilio Willems, que nessa época era docente da divisão de estudos pós-graduados da escola e chefe da Cadeira de Antropologia da FFCL. Isso seguramente foi decisivo à transferência de Gioconda para aquela mesma cadeira em 1944.

Como colaboradora de Willems, ela participaria de duas importantes pesquisas nos moldes dos estudos de comunidades. ${ }^{8}$ Cunha: tradição e transição em uma cultura rural do Brasil, ambicioso livro publicado pelo professor alemão, teve recepção bastante desfavorável. ${ }^{9}$ Curiosamente, a própria Gioconda engrossou o coro: uma resenha publicada em 1949 na Revista do Museu Paulista sinalizou seu "distanciamento dos aspectos mais problemáticos dos estudos de comunidade" (Ciacchi, 2007a:187) e, provavelmente, estremeceu as relações com Willems.

Nesse mesmo ano, ela foi contratada definitivamente como auxiliar de ensino da Cadeira de Antropologia e, com isso, sua situação funcional se estabilizou. A partir de então Gioconda

\footnotetext{
7 Nesse Centro participou em 1939 do projeto "Pesquisas no campo da sociologia econômica"- sobre a "taxa de transmissão da profissão de pais a filhos" e dirigiu as "Pesquisas sobre criminalidade infantil" realizadas pela turma do segundo ano em 1941 (USP, 1953:645-646; Mussolini, 1965:4).

8 A primeira delas se realizou na localidade de Cunha entre 1945 e 1946; e a segunda na ilha de Búzios em 1947. Os resultados da última seriam publicados em 1952 como Buzios Island: A Caiçara Community in Southern Brazil (Gioconda figura como colaboradora).

9 Em São Paulo, devido à crítica contundente de Caio Prado Jr., seguida por outras desferidas da Cadeira de Sociologia I (Jackson, 2003:123). No Rio de Janeiro, o livro seria depreciado por Alberto Guerreiro Ramos (Arruda, 2001:238).
} 
realizou uma carreira inteiramente associada à USP. A saída de Willems para a Universidade de Vanderbilt nos Estados Unidos e a indicação de Egon Schaden (1913-1991) como substituto permitiram que ela assumisse interinamente a posição de segunda assistente. A passagem oficial para o posto seguinte na hierarquia veio em 1951, quando ela assumiu a vaga de primeira assistente deixada por Schaden, já empossado como titular da cátedra.

$\mathrm{Na}$ sucessão, só o assistente, por ter concluído o doutoramento, tinha condições de assumir a cátedra. A antropóloga não conseguiria, aliás, realizar o intento nem mesmo quando nova oportunidade se apresentou em 1967: Schaden se aposenta prematuramente tendo em vista um convite para assumir a Cadeira de Etnologia da Universidade de Bonn (Pereira, 1994:253) e indica João Baptista Borges Pereira como seu substituto interino. Essas mudanças agravaram conflitos internos à cadeira, levando Gioconda a articular, por meio de um manifesto (assinado pela quase totalidade do quadro de assistentes) submetido à Congregação da FFCL, a contratação de um professor estrangeiro para o cargo de catedrático. ${ }^{10}$ Nessa instância, a iniciativa seria encampada por Florestan Fernandes, José Arthur Giannotti, entre outros, mas em função da sucessão de eventos que acometeram a faculdade - a ocupação dos prédios pelos estudantes, o ataque à "Maria Antônia", a reforma universitária e a própria morte precoce de Gioconda - a discussão ficou em suspenso e não foi retomada posteriormente.

Embora o legado intelectual de Gioconda tenha sido reivindicado pela geração seguinte de antropólogos e os resultados

\footnotetext{
${ }^{10}$ Conforme o registro das atas da Congregação da FFCL (USPa, 1968), assinaram o manifesto Eunice Durham, Ruth Cardoso, Amadeu Lana, Renate Viertler, José Francisco Quirino e Antônio Augusto Arantes. Tekla Hartmann, por discordar da "maneira" como a proposta foi apresentada, não assinou o documento e apresentou declaração separada. Para contornar a mobilização, João Baptista sugeriu a contratação de um professor estrangeiro, mas na condição de colaborador e Ruy Galvão de Andrada Coelho (1920-1990) - nessa ocasião, chefe da Cadeira de Sociologia II e presidente do Conselho TécnicoAdministrativo (CTA) - o apoiou.
} 
parciais de suas pesquisas sobre as sociedades caiçaras brasileiras reconhecidos por constituírem interpretações pioneiras, sofisticadas e promissoras, ela não concluiu a tese de doutorado. Compreender essa espécie de "bloqueio" não é uma tarefa simples. Seja como for, qualquer tentativa nessa direção não pode ignorar a situação de insegurança e dilaceramento a que, como outras professoras de sua geração, ela esteve sujeita. As dificuldades subjetivas interpostas por ela para cumprir os requisitos formais que viabilizariam o pleito à cátedra bem poderiam ser interpretadas nos termos da violência simbólica: a "autoexclusão" que substitui a "exclusão expressa" e "torna a aproximação de um espaço masculino [...] uma prova terrível" (Bourdieu, 2002:52).

\section{2}

Gilda nasceu na cidade de São Paulo em 1919, mas viveu a infância na zona rural de Araraquara, onde seus pais eram proprietários da fazenda Santa Isabel (Pontes, 1998:160). Muito mais tarde, essa experiência seria lembrada como decisiva para a conformação de sua percepção intelectual:

Eu e meus irmãos passamos os primeiros anos de vida numa casa isolada de fazenda, longe do apelo dos livros, das revistas, [...] da escola e em contato direto com o mundo exterior: as árvores, os bichos, o sol a água, as estações. [...] O saber não chegava até nós pelos livros, as coisas não batiam prontas à nossa porta, faziam-se aos nossos olhos. [...] Acho que foi esse aprendizado sensorial, carnal do mundo, que desenvolveu em mim a percepção venatória. [...] Percepção a meio caminho da ciência e da arte e que, a meu ver, deve orientar o crítico (Mello e Souza, 2007:202; ênfases adicionais).

O período também seria marcado pelo convívio com o escritor Mário de Andrade, primo de seu pai. Ele costumava passar parte das férias na fazenda Santa Isabel. A convivência aumentaria no início da adolescência. A crise de 1929 deixou a 
família numa situação financeira periclitante $e$ os filhos mais velhos tiveram que estudar na capital. Gilda e a irmã foram acolhidas na casa da tia-avó, que morava com o filho escritor. Desde então, o primo passaria a influir diretamente em sua formação (Escorel, c2010; Mello e Souza, 1981-4:144-145).

Ela completou os estudos secundários no Colégio Stafford internato feminino de inspiração anglo-americana -, situado nos Campos Elíseos, então um bairro cativo da elite paulistana. Nutrindo aspirações literárias e aconselhada por Mário, Gilda ingressou no Curso de Filosofia da FFCL em 1937. Esperava assim obter o preparo para seguir a carreira de escritora ficcionista (Mello e Souza, 2007:201). O ambiente dos primeiros anos da faculdade, com turmas pequenas e relativamente homogêneas proporcionou intensa convivência com os colegas. Afinidades sociais, políticas e afetivas contribuíram para que ela integrasse um círculo seleto de amizades, que pouco depois se projetaria na cena cultural com a revista Clima. O grupo também foi "pródigo" em encontros afetivos: Gilda e Antonio Candido, casados em 1943, foi um deles. ${ }^{11}$

Gilda se formou em 1940 e iniciou seu envolvimento profissional na Seção de Ciências Sociais no ano seguinte: esteve entre os licenciados escolhidos por Paul-Arbousse e Roger Bastide para colaborar com o Centro de Pesquisas e Documentação Social. ${ }^{12}$ A aproximação com o professor se estreitou nos semestres seguintes e ela foi convidada para trabalhar na Cadeira de Sociologia I. A nomeação, entretanto, só viria em 1943, como terceira assistente extranumerária de tempo parcial; em 1945 passou a segunda assistente; e com a saída de Lavínia da Costa

\footnotetext{
${ }^{11}$ Segundo Heloísa Pontes (1998:125), o grupo reunia cerca de vinte pessoas. Entre os mais empenhados na revista estavam, além de Gilda e Antonio Candido, Decio de Almeida Prado, Lourival Gomes Machado, Maria de Lurdes dos Santos, Paulo Emilio Salles Gomes, Ruth Alcântara e Ruy Coelho. Outros casais originados pelo grupo foram Maria de Lourdes e Lourival, e Ruth e Decio.

${ }^{12}$ Ela orientou alunos do terceiro ano numa pesquisa bibliográfica sobre "Sociologia mitológica" em 1941 (USP, 1953:646).
} 
Villela, Gilda permaneceu como a única assistente. ${ }^{13}$ Em 1950, orientada por Bastide, defendeu a tese A moda no século XIX e obteve o título de doutora. ${ }^{14}$

Como sugere Heloísa Pontes (1998:188-190), a trajetória de Gilda seria marcada por certa "marginalidade", no sentido sociológico do termo. A começar pelos tempos de Clima, sua participação sofreu as restrições de uma divisão sexual do trabalho intelectual, que ora a designou às tarefas editoriais menos visíveis, ora a relegou às seções menos prestigiadas (como a de contos). Já como socióloga, além do retardamento de sua carreira docente pelos entraves associados à lógica patriarcal imperante, sua tese sobre a moda sofreria os efeitos desvalorizadores da hierarquia acadêmica e científica que sancionava a escolha dos objetos de estudo, a validade das evidências mobilizadas, a legitimidade das formas de exposição e explicação. Tensionada pelas polaridades

${ }^{13}$ Ver o "Relatório do Professor" redigido por Bastide e anexo ao currículo de Gilda (Mello e Souza, 1950:13-14). De 1942 a 1949, ela se incumbe dos seminários referentes aos seguintes temas: "Sociologia geral"; "Arte e vida social"; "Pesquisa sobre o gosto brasileiro no $2^{\circ}$. Reinando, através de anúncios de jornais"; "Sociologia religiosa", "Sociedades primitivas", "Técnicas de histórias de vida", "Sincretismo religioso no Brasil"; e "Sociologia da moda"(USP, 1953:647-649).

${ }^{14}$ Uma nota sobre a defesa da tese, curiosamente redigida por Maria Isaura $e$ publicada na seção "Noticiário" da Revista de História, permite entrever a recepção acadêmica imediata do trabalho. A banca examinadora foi composta exclusivamente por homens - Roger Bastide, Sérgio Milliet, Alfredo Ellis Jr. e João Cruz Costa - e esse fato determinou o tom das críticas apresentadas. Foi recorrente nas arguições a questão relativa à autonomia da dimensão estética, obrigando Gilda a combater os julgamentos unilaterais advindos tanto da crítica de arte quanto da sociologia $e$ a defender a especificidade da moda como fenômeno situado no domínio fronteiriço de uma sociologia estética. A controvérsia mais incômoda, entretanto, se deu em torno das formulações apresentadas por ela acerca das relações de gênero. Cruz Costa sustentou que as "diferenças" entre as duas morais sexuais não devem ser "tão fortes" como caracterizadas na tese, pois, "na realidade", elas "se completam", demonstrando seu desconforto com as ideias de dominação e conflito pressupostas na análise; Ellis Jr., por sua vez, censurou a escolha do assunto e "lamenta que, sendo tantos os problemas brasileiros por estudar, tenha a candidata escolhido um tema geral" (Queiroz, 1951:462). 
cultura feminina tradicional $e$ modernos modelos de comportamento, literatura e crítica cultural, sociologia e filosofia, Gilda vivenciou a intersecção entre universos de atividade díspares. Situação que informa a capacidade reflexiva, o distanciamento e a liberdade de composição. Ironicamente, tais características vieram a ser extremamente valorizadas na conjuntura acadêmica atual. Isso ajuda a explicar porque somente nos últimos decênios seus trabalhos - a começar por sua tese de doutoramento - voltaram a ser reeditados e, com isso, a alcançar uma circulação mais ampla.

Conforme mencionado anteriormente, entre 1953 e 1954, Roger Bastide retornou definitivamente à França e indicou Florestan Fernandes como substituto. Pouco depois, Gilda migrou para a Seção de Filosofia. ${ }^{15}$ Embora o renome de Florestan projete sobre essa sucessão de eventos um viés normalizador, não parece demais problematizar a opção de Bastide. Nessa ocasião, Gilda também reunia credenciais que encorajariam uma ambição ao cargo. Ela tinha fundado e participado ativamente da revista Clima, que se tornou um marco da vida intelectual paulista. Somados os períodos em que estivera encarregada, sucessivamente, das funções de terceira, segunda e única assistente - sem contar o tempo inicial de colaboração informal -, ela totalizara cerca de doze anos trabalhando junto à cadeira. Ocupava o segundo cargo da hierarquia acadêmica. Defendera o doutorado com antecedência e apresentando um trabalho que,

${ }^{15}$ Como professora de estética ela também enfrentaria resistências num departamento que apregoava a familiaridade com as teorias em detrimento do contato direto com as obras. Mas isso não a impediu de desempenhar funções importantíssimas: Gilda chefiou o Departamento de Filosofia em seu período mais difícil (1969-1972), tensionado externamente pelas perseguições do regime militar e, internamente, por disputas renhidas entre professores; nesse período também fundou a revista Discurso, que se tornou uma referência para os estudos filosóficos no país (Miceli e Mattos, 2007); finalmente, devido à sua posição institucional, viabilizou a carreira acadêmica tardia de antigos companheiros de Clima: tanto Decio de Almeida Prado quanto Paulo Emilio Salles Gomes defenderiam suas teses na área de estética sob orientação formal de Gilda (Pontes, 1998:203). 
visto em perspectiva, se inscreve entre as melhores realizações do programa de pesquisas concebido pelo professor francês. Comparada a Florestan, além da origem social muito mais favorável, Gilda carecia apenas de um trunfo: o título de livredocente que ele obtivera justamente em 1953. Novamente, por maiores que tenham sido a capacidade de trabalho, o talento e o renome atribuídos a ele, sua indicação torna-se incompreensível sem que se considere as injunções a que estiveram sujeitas as mulheres nesse contexto. Por outro lado, até onde foi possível averiguar, Gilda não expressou descontentamento por ter sido preterida, fato que pode ser interpretado como um indício da autoexclusão típica das manifestações de violência simbólica.

\section{3}

Maria Isaura nasceu na cidade de São Paulo em 1918. Os laços de parentesco de sua família remontam, tanto pelo lado materno (Queiroz Telles), quanto paterno (Pereira de Queiroz), a diferentes ramos da oligarquia cafeicultora paulista (Queiroz, 1992:14-15; Pulici, 2004:92). Graças a essa origem social privilegiada pôde receber dos pais, mais do que estímulo escolar, o "decidido apoio" de a "eximir das preocupações com as lides caseiras" (Queiroz, 1990:20). Como ela mesma sugeriu, a circunstância de viver num centro urbano em acelerado processo de modernização e a mentalidade arejada de sua família influíram no percurso bastante linear de sua vida escolar:

Entrei no Jardim de Infância da Praça da República, porta de entrada para a Escola Normal da Praça, onde minha mãe e minhas tias todas já haviam estudado e saído formadas professoras primárias; meus avós achavam que suas filhas deviam estudar em escolas públicas para serem iguais a todas as demais jovens. Assim, estudei no Jardim de Infância, na Escola Primária, na Secundária, me formei normalista, sempre na Praça da República (Queiroz, 2000:34; ênfases adicionais). 
Ao completar o curso em 1936, no entanto, a jovem não continuou o caminho trilhado pelas mulheres de sua família. Depois de trabalhar por quatro anos na Santa Casa de Misericórdia de São Paulo, ela tencionava seguir os passos de outra tia, Carlota Pereira de Queiroz, e tentar a carreira de medicina. ${ }^{16}$ Defrontada, porém, com os conhecimentos exigidos pelo vestibular na área e ciente das restrições impostas pelo currículo do curso normal, optou pela Seção de Ciências Sociais da FFCL, que lhe pareceu oferecer maiores chances de aprovação.

Maria Isaura encarou com relativa naturalidade o ingresso na FFCL. Como recordaria muitos anos depois, no momento inicial "não me ressenti dessa alteração fundamental de hábitos que geralmente marca a penetração em ambientes desconhecidos". Tudo lhe pareceu muito familiar: a começar pelo espaço físico, passando pelos colegas e chegando aos próprios professores. O estranhamento, entretanto, surgiu quando os primeiros trabalhos de aproveitamento foram solicitados: "Foi então que me dei conta de que penetrara noutro nível de raciocínio e de exigências, num outro nível intelectual" (Queiroz, 1990:11).

Em seu terceiro ano na FFCL Maria Isaura acompanhou o curso "Sociologia dos fenômenos místicos" (USP, 1953:649), ministrado por Roger Bastide. O tema estava entre os principais objetos de reflexão do professor e também direcionaria de maneira decisiva os estudos da aluna. ${ }^{17}$ Ela se formou em 1949 e no ano seguinte passou a integrar a Cadeira de Sociologia I como "instrutora extranumerária", situação que só se estabilizou em 1951, quando foi alocada na vaga de auxiliar de ensino. A

\footnotetext{
${ }^{16}$ Formada em medicina em 1926, Carlota esteve entre as primeiras mulheres a seguir a carreira. Integrando a terceira cadeira de clínica médica da Faculdade de Medicina do Rio de Janeiro, chegou a chefiar o laboratório de clínica pediátrica da instituição. Também foi eleita deputada federal em 1934 (CPDOC, c2014).

${ }^{17}$ De acordo com Fernanda Peixoto (2000:26), em seu "período francês" Bastide publicaria, ao todo, quatro artigos voltados ao tema do misticismo. Tais reflexões seriam aprofundadas ainda $1931 \mathrm{com}$ a publicação do livro Les problèmes de la vie mistique.
} 
182 Jogo de damas: trajetórias de mulheres nas ciências sociais paulistas

progressão junto à cadeira parece relacionada ao entrosamento com a linha de trabalho de Bastide. Essa sintonia se manteve ao longo de toda a década e mesmo após o retorno definitivo dele à França.

Maria Isaura permaneceria formalmente vinculada à Cadeira de Sociologia I - a partir de 1956 como "assistente" 18 - até 1958, quando se transferiu para desempenhar a mesma função junto à Cadeira de Sociologia II, então chefiada por Fernando de Azevedo e que tinha Ruy Coelho e Azis Simão como primeiro e segundo assistentes respectivamente (Antonio Candido desligou-se da cadeira nesse mesmo ano). Entretanto, as informações contidas no currículo da professora indicam que, nesse período (mais precisamente de 1951 a 1960), ela esteve mais presente na Ècole Pratique des Hautes Études, $6^{\mathrm{a}}$ Seção, Universidade de Paris, onde, sob a orientação de Bastide, defenderia a tese La guerre Saint e au Brésil: Le mouvement messianique du Contestado em 1956. O escopo de suas pesquisas sobre o fenômeno se ampliaria significativamente em $O$ messianismo no Brasil e no mundo, tese com que obteve na FFCL a livre-docência em 1963 e cuja publicação, três anos depois, lhe valeria um prêmio Jabuti pela melhor obra brasileira de ciências sociais (Queiroz, 1973:1-5).

O título de doutorado na França, a transferência para a Cadeira de Sociologia II, a livre-docência e a premiação pela Câmara Brasileira do Livro autorizaram as movimentações da socióloga no sentido de afirmar um projeto intelectual autoral firmemente ancorado na concepção de sociologia da cultura de Bastide. ${ }^{19}$ Tal projeto se consolidaria durante a década de 1960, legitimado também pela criação do Centro de Estudos Rurais ${ }^{20}$,

\footnotetext{
${ }^{18}$ No currículo constante da documentação de Maria Isaura a descrição do cargo aparece sem maiores especificações, mas parece plausível supor que se trate da função de "instrutor extranumerário".

${ }^{19}$ Essas movimentações são flagradas por Luiz Carlos Jackson (2003:90-93) em sua análise da trajetória e da estratégia de publicação adotada pela socióloga.

${ }^{20}$ A mudança para Centro de Estudos Rurais e Urbanos, sinaliza a posterior redefinição e diversificação das linhas de pesquisa do grupo.
} 
em 1964, e pela revista Cadernos CERU, publicada a partir de 1968. Inicialmente dedicado ao estudo do mundo rural brasileiro, o Centro reforçaria sempre a pesquisa de campo e o trabalho em equipe. A revista, por sua vez, serviria como principal meio de divulgação tanto dos trabalhos quanto da perspectiva teórica do grupo - composto majoritariamente por mulheres -, que acompanhava a formação adquirida por Maria Isaura $e$ atualizava a orientação estabelecida por Bastide.

A repercussão dos livros que ela publicou, alguns deles reconhecidos internacionalmente, garantiu à socióloga grande prestígio. Prestígio certamente suficiente para que ela ousasse concorrer à cátedra em algum momento. Por exemplo, o concurso da Cadeira de Sociologia II disputado por Ruy Coelho e Octavio Ianni, em 1964, o que sabidamente não ocorreu. Com a indicação do primeiro para a chefia da cátedra - cargo que já ocupava interinamente desde 1961 com a saída de Fernando de Azevedo para assumir a Secretaria Municipal de Educação e Cultura do governo Prestes Maia -, Azis Simão passaria à função de primeiro assistente e Maria Isaura à de segunda assistente.

Maria Isaura foi a única mulher dessa primeira geração de cientistas sociais paulistas a acompanhar, em termos quantitativos, o padrão de produtividade de seus colegas mais consagrados. ${ }^{21}$ Produziu uma obra extensa e variada, transitando entre a sociologia da cultura e a sociologia política. ${ }^{22}$ Também alcançou projeção nos cenários científico e cultural mais amplos, assumindo papel de destaque em instituições como a Sociedade Brasileira para o Progresso da Ciência. Nessa direção, faltou a ela apenas a cátedra, que aparentemente não teve interesse em disputar. Segundo o argumento desenvolvido aqui, essa recusa pode ser

\footnotetext{
${ }^{21} \mathrm{~A}$ apreciação pode ser conferida no levantamento das publicações das Cadeiras de Sociologia I e II entre os anos de 1954 e 1969 realizado por Carolina Pulici (2008:245-316).

${ }^{22}$ Para uma análise que insere os trabalhos da autora sobre o mandonismo local numa das vertentes da sociologia política no Brasil, ver André Botelho (2003:59$65)$.
} 
184 Jogo de damas: trajetórias de mulheres nas ciências sociais paulistas

interpretada como uma atitude subjetivamente compatível com a estrutura patriarcal do regime de cátedras.

\section{4}

Paula nasceu em Santos no ano de 1926. Os pais, Rafael e Cecília Beiguelman, eram judeus emigrados da Polônia e provavelmente aportaram em Santos após a Primeira Guerra Mundial. A situação material da família não fora confortável. Viveram num bairro operário, no qual a mãe se dedicou aos afazeres domésticos e o pai ao comércio prestamista como principal meio de vida. Teria sido um fator favorável, entretanto, o incentivo intelectual que eles puderam oferecer aos filhos:

Não obstante as dificuldades que meu pai e minha mãe enfrentaram como imigrantes na cidade de Santos, onde nasci num bairro operário, eles conseguiram propiciar [...] uma boa formação (cultura musical, inclusive) [...]. Além de uma mãe sempre atenta e preocupada com nosso desempenho escolar, tínhamos em casa um ambiente cultural estimulante, porque meu pai era um leitor voraz de literatura universal e um grande agitador cultural (Beiguelman, c2004).

O itinerário escolar de Paula se deu inteiramente na rede pública de ensino. Já no início de 1940, ela ambicionava continuar os estudos na cidade de São Paulo. A idade e a carência de recursos constituíam, no entanto, sérios impedimentos. Foram conhecidos que a avisaram sobre a possibilidade de ingresso no Curso de Ciências Sociais e Políticas da FFCL, mesmo para quem, como ela, "se apresentaria sem ter cursado colegial ou préuniversitário" (Beiguelman, 2006:192).

Acompanhada pela mãe à capital, Paula realizou o exame de ingresso, e, devido ao número reduzido de candidatos e à disponibilidade de vagas, foi aprovada. Restava então o problema de como ela se manteria sozinha na cidade. A solução definitiva surgiu por iniciativa da própria jovem, que apelou à diretoria da faculdade tendo em vista algum emprego remunerado $e$, 
inesperadamente, obteve uma bolsa de estudos (Beiguelman, 2006:193). Como a contrapartida era o bom desempenho escolar, parece que Paula correspondeu à expectativa, pois contou com o auxílio até se formar. Todavia esse bom rendimento não a livrou de adversidades:

Sentíamos dificuldade para acompanhar as exposições em francês, principalmente no começo. [...] Mas felizmente minha classe contava com o auxílio de uma professora querida, Gioconda Mussolini, assistente do Prof. Emílio Willems e formada numa das primeiras turmas. [...] Gioconda assistia às aulas conosco e, quando soltava sua simpática risada, ficávamos sabendo que o professor havia dito [...] algo engraçado. Mas o mais importante era que ela tomava apontamentos que, em seguida, repassava para nós, acrescentando oralmente as explicações necessárias (Beiguelman, 2006:193-194).

Parece evidente que as dificuldades não se restringiam ao idioma. O papel "assistencial" exercido por Gioconda revela o descompasso entre as exigências do ensino implicitamente elitista da faculdade e a formação deficiente da maioria dos estudantes. Mas a extração social de origem $e$ a circunstancial ascendência imigrante conformariam o substrato do ímpeto para a inserção profissional e o investimento na carreira. Isso ajuda a explicar a inserção profissional de Paula imediatamente após a obtenção do diploma em 1945. No entanto, diferente do destino profissional comum aos formados pela FFCL - o magistério -, a jovem se empregou no Departamento de Serviço Público, transferindo-se pouco depois para o Departamento Estadual de Estatística (Beiguelman, 2006:194).

Paula permaneceu nesse posto até 1949, quando surgiu uma oportunidade de retorno à FFCL: integrar a Cadeira de Política, desfalcada pelas saídas do professor George Gurvitch e 
186 Jogo de damas: trajetórias de mulheres nas ciências sociais paulistas

do assistente Benedicto Ferri de Barros. ${ }^{23} \mathrm{O}$ convite partira de Lourival Gomes Machado, que, até a chegada de Charles Morazé - acertada para o segundo semestre do mesmo ano -, ocupava interinamente a regência da cátedra. Ele precisou recompor o quadro de assistentes e requisitou o comissionamento da licenciada, que efetivamente foi designada para o cargo de auxiliar de ensino. $\mathrm{O}$ convite não partia do zero. $\mathrm{O}$ contato com o professor remontava a um curso sobre o pensamento político de Jean-Jacques Rousseau, no qual aluna teria se destacado (Beiguelman, 2006:194).

No primeiro ano como auxiliar, ela colaborou com Morazé, já à frente da cadeira. Com a saída do professor francês, Lourival foi indicado novamente chefe interino da cadeira, cargo que assumiu definitivamente após realizar (sem concorrentes) o primeiro concurso de provimento de cátedra da Seção de Ciências Sociais em 1952. Nesse intervalo, Paula transitou da função de "assistente em caráter de substituição" para a de primeira assistente e suas responsabilidades aumentaram. ${ }^{24}$

No final de 1961, ela obteve o título de doutora com a tese Teoria e ação no pensamento abolicionista. E no começo do ano seguinte, Lourival se afastou para assumir o cargo de diretor do Departamento de Assuntos Culturais da Unesco em Paris,

\footnotetext{
${ }^{23}$ Benedicto foi nomeado em 1944 (USP, 1953:670). Aparentemente, a saída do assistente foi provocada por sua insatisfação com o modelo de ensino da FFCL (Garcia, 2002:89).

${ }^{24}$ Ela ministrou os cursos básicos - "Introdução à ciência política" e parte das disciplinas "História das ideias políticas" e "Instituições políticas"-, orientou pesquisas bibliográficas e de campo, bem como o "curso de especialização" (depois equiparado ao mestrado): uma pesquisa dedicada à Inconfidência Mineira. Trabalhos relacionados ao projeto foram publicados em revistas $e$ coletâneas: ver, por exemplo, Nely Pereira Pinto Curti (1966) e Célia Nunes Galvão Quirino dos Santos (1965 e 1966). Em 1960, é introduzido no currículo o curso "Instituições políticas brasileiras", que também ficou ao encargo da assistente. Todas as atividades elencadas foram coligidas no Memorial (Beiguelman, 1967).
} 
deixando Paula na regência interina cadeira. ${ }^{25}$ Embora as atividades desempenhadas pela professora nos anos posteriores não encontrem registros na documentação disponível, a defesa de livre-docência com a tese Contribuição à teoria da organização política brasileira, mais a apresentação de outra - A formação do povo no complexo cafeeiro - para o concurso de cátedra de 1968, sinalizam o rumo seguido: a habilitação para a titularidade da cátedra.

O concurso para a Cadeira de Política transcorreu numa circunstância adversa devido ao recrudescimento da ditadura militar e da radicalização do movimento estudantil. Paula concorre como candidata "natural". O desafiante, Fernando Henrique Cardoso, apresentou a tese Política e desenvolvimento em sociedades dependentes. A disputa expressou de modo paradigmático tensões que permeavam o ambiente acadêmico da FFCL: de um lado, Paula, descendente de imigrantes, mulher, solteira, professora excepcional, integrante de uma cadeira subalterna, sem influência perante as instâncias de direção universitárias, "prata da casa" e apresentando um trabalho sob o tema da formação; de outro, Fernando Henrique, herdeiro de família tradicional, homem, casado, pesquisador prolífico, integrante de uma cadeira dominante, influente junto aos órgãos diretivos da universidade, com carreira internacionalizada $e$ apresentando uma tese sob o tema modernização. Favoravelmente a ele contariam, ainda, as movimentações de Florestan Fernandes e José Arthur Giannotti na Congregação. A

\footnotetext{
${ }^{25}$ Além das atribuições relativas ao bacharelado cabe mencionar: o estudo "Atitudes, opiniões e comportamento político"; os seminários "Teoria política do desenvolvimento" e "Problemas metodológicos"; a responsabilidade quanto as dissertações de mestrado $e$ as teses de doutorado; $e$ a pesquisa coletiva "Organização política brasileira no período republicano", desenvolvida com financiamento da recém-criada Fapesp. Resultados parciais desse projeto foram publicados por Paula Beiguelman (1968) e Maria do Carmo Campello de Souza (1968).
} 
atuação de Ruy Coelho nessa instância, mais o sentimento difuso de solidariedade da comunidade acadêmica valeram à ela. ${ }^{26}$

Os dois candidatos foram aprovados, mas a banca examinadora escolheu Fernando Henrique por unanimidade. Independente do impacto no plano pessoal, o resultado representou um instantâneo do desenvolvimento das ciências sociais paulistas. Num polo, em ritmo acelerado de institucionalização, estava o projeto de afirmação acadêmica lastreado na Cadeira de Sociologia I. Noutro, em posição retardatária nesse processo, o projeto implementado junto à Cadeira de Política.

Imediatamente após a derrota, Paula se transferiu para a Cadeira de História da Civilização Brasileira, chefiada por Sergio Buarque. No ano seguinte, entretanto, os dois candidatos seriam aposentados compulsoriamente pelo regime militar (Adusp, 2004:48). Para ela, porém, tais episódios marcaram a interrupção da vida acadêmica e projetaram uma sombra sobre toda a sua trajetória. A partir daí suas atividades intelectuais tomam o rumo da militância política. Outro desfecho significativo seria o casamento ocorrido pouco depois (Beiguelman, 2006:197).

${ }^{26} \mathrm{O}$ foco dos embates foi a composição da banca examinadora. As disputas entre as cadeiras de sociologia e o clima de prevenção entre Fernando Henrique e Florestan beneficiaram Paula (Pulici, 2008; Romão, 2006; Fernandes, c1968). $\mathrm{O}$ resultado foi equilibrado: a Congregação indicou Ruy Coelho e Sérgio Buarque de Holanda. O CTA - presidido por Ruy Coelho - indicou os outros integrantes: Orlando de Carvalho, José Honório Rodrigues e Victor Nunes Leal (USP, 1968a e b). Não é demais ressaltar que Paula foi a única mulher envolvida. José Almino de Alencar lembra que "Paula Beiguelman [...] esperava havia anos que a cátedra de política vagasse para se candidatar. [...] Era evidente que se ele concorresse ela não teria a menor chance. Como reinava um certo espírito de companheirismo no meio das ciências sociais, a decisão dele não foi muito bem aceita, foi julgada bastante oportunista pelos colegas" (Leoni, 1997:138). 
As trajetórias reconstituídas aqui não são apenas reveladoras das constrições com as quais se deparou essa primeira geração de mulheres no interior da FFCL-USP. Elas também lançam luz sobre as vias disponíveis àquelas que afirmaram nome próprio no universo profissional então em constituição. Certamente, a condição feminina não foi o único fator determinante, mas tampouco é possível negligenciá-la quando se almeja compreender os dilemas enfrentados $e$ as realizações alcançadas nesse contexto.

De saída, a comparação entre elas realça os mesmos aspectos que caracterizam a clientela da FFCL. Em função da origem social desfavorável, Gioconda e Paula buscaram uma inserção profissional prévia (como professora primária $e$ funcionária da administração pública estadual respectivamente), que lhes permitiu, dadas as oportunidades abertas pelo comissionamento, uma colocação acadêmica mais estável. Gilda $e$ Maria Isaura, oriundas de famílias melhor posicionadas, tiveram condições de arcar com as incertezas decorrentes das diversas modalidades de recrutamento voluntário ou informal que antecederam a contratação como instrutoras ou auxiliares. Nos casos das descendentes de imigrantes, a busca precoce por colocação esteve também associada à escolha de objetos de pesquisa que lhes projetou ao centro do debate intelectual, enquanto aquelas provenientes dos ramos tradicionais da oligarquia paulista optaram por assuntos com menor cotação na hierarquia acadêmica. Paradoxalmente, a via de inserção mais estável obtida pelas duas primeiras reduziu as chances de contornar os constrangimentos impostos pelo regime de cátedras, enquanto as duas últimas contaram com maior margem de movimentação.

A exemplo dos colegas homens, Gioconda, Maria Isaura, Gilda e Paula também foram beneficiadas pela presença da missão francesa, bem como do padrão de trabalho intelectual $e$ científico gestado nas primeiras décadas de funcionamento das novas instituições paulistas. Diferente deles, entretanto, elas não contaram com uma tradição consolidada por gerações dedicadas 
190 Jogo de damas: trajetórias de mulheres nas ciências sociais paulistas

ao trabalho profissional na qual pudessem se espelhar, nem tiveram a seu favor uma organização acadêmica ajustada às suas disposições de gênero e pronta a reconhecer como legítimas suas investidas.

Em termos mais concretos, duas diferenças podem ser destacadas. A primeira se refere ao entrelaçamento das dimensões afetiva e profissional. Para os homens, o casamento não se mostrou incompatível com a carreira intelectual $e$, em alguns casos, o arranjo familiar impulsionou suas vidas profissionais. Como bem notou Sylvia Garcia (2002:62) em relação a Florestan Fernandes, a

total dedicação de Myriam Rodrigues ao casamento permitiu e sustentou, cotidianamente, a realização do sonho de juventude do marido de fazer parte de uma "família bem organizada", conforme o padrão da vida privada das camadas médias paulistanas de meados do século passado.

Mas esse suporte não se atém à dimensão privada. $\mathrm{O}$ grau de investimento que o sociólogo pôde realizar na vida acadêmica é indissociável dessa "dedicação total" da esposa ao casamento.

Outra variante nesse sentido foi a união formada por Lourival e Maria de Lourdes. Conforme indicou Heloísa Pontes (1998:126), enquanto ele se incumbiu da direção de Clima, ela atuou como secretária, assegurando "o apoio logístico e afetivo" necessário à execução da revista, bem como à "realização profissional e intelectual" do marido. Mesmo formada pelo Instituto de Educação, especializada em administração escolar, assistente de Fernando de Azevedo e ministrando o curso de didática na FFCL, Maria de Lourdes não escreveu nenhum artigo para a revista. Embora desigualmente, Lourival pôde combinar o casamento com as funções de catedrático, o comentário regular de política internacional na imprensa e uma carreira bem-sucedida como crítico de artes plásticas. A produção intelectual de Maria de 
Lourdes se restringiu a traduções, boa parte delas realizadas em parceira com o marido. ${ }^{27}$

Quando se observa a situação pelo ângulo das mulheres, a opção pela carreira intelectual aparece como entrave à realização afetiva nos moldes tradicionais, ou seja, por meio do casamento com filhos. Dentre as trajetórias examinadas, apenas Gilda se casou. Paula, só pôde fazê-lo após ter a carreira brutalmente interrompida. Maria Isaura e Gioconda permaneceram solteiras. Recorrendo aos esquemas indicados anteriormente, a busca por realização profissional integral esteve atrelada à adoção do "modelo radical" de feminilidade. A opção por preservar o "modelo tradicional", mesmo que parcialmente como fez Gilda, permitiu a conciliação entre as atribuições profissionais $e$ os encargos advindos do casamento, mas reduziu significativamente a margem de investimento necessário para que se pudesse entrar à vera na disputa pelas posições de maior prestígio e poder acadêmicos.

A segunda diferença se relaciona às realizações profissionais. Apesar das conquistas desigualmente alcançadas, elas não puderam igualar, simultaneamente, todas as dimensões abrangidas pelos feitos daqueles mais bem-sucedidos entre os homens. Sobretudo na Seção de Ciências Sociais, nenhuma mulher conquistou a titularidade da cátedra universitária. ${ }^{28} \mathrm{Em}$ consonância ao argumento desenvolvido aqui, esse fator sugere a existência de uma assimetria de gênero em favor dos homens que se mostrou impraticável superar. Ainda mais considerando que tal impedimento operava tanto no âmbito das estruturas objetivas, como por meio da internalização, em mulheres e homens, da

\footnotetext{
${ }^{27}$ Notadamente dos escritos de Jean-Jacques Rousseau e a História da civilização ocidental, de Edward Macnall Burns, publicados pela Editora Globo em 1958 e 1959 respectivamente.

${ }^{28}$ Salvo engano, a primeira mulher a obter a titularidade de uma cátedra na FFCL foi Noemy da Silveira Rudolfer. Ela substituiu oficialmente Lourenço Filho na Cadeira de Psicologia Educacional em 1935. Alice Canabrava disputou com Astrogildo Mello o concurso da Cadeira de História da Civilização Americana em 1946 e foi preterida (Canabrava, 2005).
} 
lógica patriarcal prescrita pelo sistema de cátedras. A impossibilidade de obter a cátedra e de igualar as conquistas masculinas foi incorporada pelas mulheres e se fez visível pelas hesitações ou autoexclusões que atravancaram em graus diferentes a progressão da carreira acadêmica de cada uma delas.

Paula foi a única dessa quadra examinada que desafiou essa interdição implícita. E o fez duas vezes: ao exercer efetivamente a chefia interina da Cátedra de Política - por sete anos informalmente e menos de um com o reconhecimento oficial das instâncias universitárias; $e$ ao disputar a titularidade da cadeira participando do concurso de 1968. Mas esse "feito" deve ser sopesado com base em dois aspectos nada desprezíveis: a posição de Paula na coorte geracional $e$ a hierarquia institucional das cadeiras que compunham a Seção de Ciências Sociais. Não parece uma coincidência fortuita que a única mulher desse grupo a disputar uma cátedra tenha sido justamente a mais jovem. De certo modo, Gioconda, Gilda e Maria Isaura ampliaram o universo dos possíveis que coube a Paula levar ao limite. Além disso, as três pioneiras tiveram as carreiras acadêmicas tolhidas por ocuparem posições que se tornaram mais valorizadas em função da progressiva institucionalização de suas especialidades. Em outros termos, Paula teve o seu trajeto acadêmico temporariamente desobstruído pela vinculação a uma cadeira que foi sendo deslocada para uma posição subalterna frente às cátedras de Antropologia e Sociologia.

Tomar em conjunto as diferenças entre as trajetórias de mulheres e homens permite considerar o desenvolvimento das ciências sociais em São Paulo de uma perspectiva inusitada. Longe de um exercício inconsequente, animado por um espírito bisbilhoteiro, o esforço de articular arranjos familiares e trajetos acadêmicos é um modo de colocar em prática, mesmo que de modo tentativo, uma forma de análise relacional. É sobretudo a partir do encaixe entre economia doméstica - a divisão de trabalho $e$ de poderes que a caracteriza - e diferentes setores do mercado de trabalho que é possível divisar as variações de "conteúdo" e a permanência das "formas" em meio às lutas 
travadas entre homens e mulheres, sejam elas no campo semântico, político ou acadêmico (Corrêa, 2003:31).

\section{Referências bibliográficas}

ADUSP. O controle ideológico na USP (1964-1978). São Paulo, Adusp, 2004.

ARRUDA, Maria Arminda Nascimento. Metrópole e cultura: São Paulo no meio do século XX. Bauru, EDUSC, 2001.

Beiguelman, Paula. Depoimento. Informe: edição especial. São Paulo, FFLCH-USP, 2004, pp.192-197.

. Processo político-partidário brasileiro de 1945 ao plebiscito. In: MOTA, Carlos Guilherme (org.). Brasil em perspectiva. São Paulo, Difel, 1968, pp.357-377.

Memorial. São Paulo, Concurso para Livre-Docência. Arquivos da Seção de Protocolo, FFLCH-USP, 1967.

BeIGUELMAN, Bernardo. Discurso proferido durante a cerimônia de outorga do título de Professor Emérito [http://www.fcm.unicamp.br/40anos/discursos/prof_dr_bernardo.doc acesso em: 13 mar. 2008].

BotelHo, André. Sequências de uma sociologia política brasileira. Dados, vol.50, nº1, 2007, pp.49-82.

BOURDIEU, Pierre. A dominação masculina. Rio de Janeiro, Bertrand Brasil, 2002.

Canabrava, Alice Piffer. História econômica: estudos e pesquisas. São Paulo, Editora Unesp, 2005.

CIACCHI, Andrea. Gioconda Mussolini: uma travessia bibliográfica. Revista de Antropologia, vol. 50, $\mathrm{n}^{\circ}$ 1, São Paulo, USP, 2007a, pp.181-222.

- As testemunhas do silêncio: Gioconda Mussolini entre lembranças e esquecimentos. Trabalho apresentado no XXXI Encontro Anual da ANPOCS, Caxambu, 2007b [http://201.48.149.88/anpocs - acesso em: 13 nov. 2008]. 
194 Jogo de damas: trajetórias de mulheres nas ciências sociais paulistas

CORREAA, Mariza. Antropólogas \& Antropologia. Belo Horizonte, Editora UFMG, 2003.

A antropologia no Brasil (1960-1980). In: Miceli, Sergio (Org.). História das Ciências Sociais no Brasil. São Paulo, Editora Sumaré, vol. 2, 1995, pp.25-106.

CPDOC. Dicionário histórico-biográfico brasileiro. Fundação Getúlio Vargas [http://cpdoc.fgv.br/acervo/dhbb - acesso em: 02 fev. 2014].

CURTI, Nely Pinto. A realidade sociopolítica nas minas em fins do século XVIII: análise ideológica da produção do grupo mineiro. Revista de História, vol. XXXIII, nº 67, 1966, pp.121-143.

ESCOREL, Ana Luisa. A menina e a mãe dela. Piauí, n ${ }^{\circ}$ 40, Rio de Janeiro; São Paulo: Editora Alvinegra, jan. 2010 [http://revistapiaui.estadao.com.br - acesso em: 2 fev. 2014].

Fernandes, Florestan. Carta para Fernando Henrique Cardoso. São Paulo, 13 mai. 1968. [http://acervo.ifhc.org.br> - acesso em: 20 jan. 2014].

FERREIRA, Oliveiros. Maria Antônia começou na praça. In: SANTOS, Maria Cecília Loschiavo dos (Org.). Maria Antônia: uma rua na contramão. São Paulo, Nobel, 1988, pp.19-26.

GARCIA, Sylvia. Destino ímpar: sobre a formação de Florestan Fernandes. São Paulo, Editora 34, 2002.

JACKSON, Luiz Carlos. Representações do mundo rural brasileiro: dos precursores à sociologia da USP. Tese (Doutorado em Sociologia) USP, São Paulo, 2003.

LEONI, Brigitte. Fernando Henrique Cardoso: O Brasil do possível. Rio de Janeiro, Nova Fronteira, 1997.

LIMONGI, Fernando. Mentores e clientelas da Universidade de São Paulo. In: MiCELI, Sergio (Org.). História das Ciências Sociais no Brasil. 2 ed. São Paulo, Editora Sumaré, vol. 1, 2001, pp.135-221.

Mello e SouzA, Gilda de. Entrevista com Gilda Rocha de Mello e Souza. In: MICELI, Sergio; MATTOS, Franklin de. (Orgs.). Gilda: a paixão pela forma. Rio de Janeiro, Ouro sobre Azul, 2007, pp.199-207. 
MICELI, Sergio. Condicionantes do desenvolvimento das Ciências Sociais. In: (Org.). História das Ciências Sociais no Brasil. 2 ed. São Paulo: Editora Sumaré, vol. 1, 2001, pp.91-133. ; MATTOS, Franklin de (Orgs.). Gilda: a paixão pela forma. Rio de Janeiro, Ouro sobre Azul, 2007.

MussolinI, Gioconda. Curriculum vitae. Arquivos da Seção de Protocolo. FFLCH-USP, 1965.

PEIXOTO, Fernanda. Diálogos brasileiros: uma análise da obra de Roger Bastide. São Paulo, Edusp, 2000.

PEREIRA, João Batista Borges. Emilio Willems e Egon Schaden na Antropologia. Estudos Avançados, vol.8, n 22, 1994, pp.249-253.

PERROT, Michelle. Mi historia de las mujeres. Buenos Aires, Fondo de Cultura Económica, 2009.

PonTES, Heloisa. Destinos mistos: os críticos do Grupo Clima em São Paulo (1940-68). São Paulo, Companhia das Letras, 1998.

PULICI, Carolina. Entre sociólogos: versões conflitantes da "condição de sociólogo" na USP dos anos 1950-1960. São Paulo, Edusp, 2008.

QUeIROZ, Maria Isaura Pereira de. Defesa da tese apresentada ao doutoramento na Cadeira de Sociologia (I) da Faculdade de Filosofia, Ciências e Letras da Universidade de São Paulo pela licenciada Gilda Rocha de Mello e Souza. Revista de História, vol.II, 1951, pp.459464. 1973.

. Curriculum vitae. Arquivos da Seção de Protocolo. FFLCH-USP,

. Discurso de agradecimento. In: OUTORGA do título de Professora Emérita a Maria Isaura Pereira de Queiroz. São Paulo, FFLCH-USP, 1990, pp.11-20.

. Carnaval brasileiro: o vivido e o mito. São Paulo, Editora Brasiliense, 1992.

. Palauras da homenageada. In: ANTUNIASSI, Maria Helena; LANG, Alice Beatriz. (Orgs.). Maria Isaura Pereira de Queiroz: a mestra. São Paulo, Humanitas, 2000, pp.34-37. 
196 Jogo de damas: trajetórias de mulheres nas ciências sociais paulistas

RINGER, Franz. O declínio dos mandarins alemães: a comunidade acadêmica alemã (1890-1933). São Paulo, Edusp, 2000.

RomÃo, Wagner. Sociologia e política acadêmica nos anos 60: a experiência do CESIT. São Paulo, Humanitas, 2006.

SANTOS, Célia Nunes Galvão Quirino dos. Curriculum vitae. Arquivos da Seção de Protocolo. FFLCH-USP, 1950.

.As sociedades secretas e a formação do pensamento liberal. Anais do Museu Paulista, tomo XIX, 1955, pp.51-59.

A Inconfidência Mineira. Anais do Museu Paulista, tomo XX, 1966, pp.137-178.

. Entrevista. Língua e Literatura. São Paulo, FFLCH-USP, vol. 1013, 1981-4, pp.134-157.

SouZA, Maria do Carmo Campello de.O processo político-partidário na Primeira República. In: MOTA, Carlos Guilherme (Org.). Brasil em perspectiva. São Paulo, Difel, 1968, pp.162-226.

SPIRANDELLI, Claudinei. Trajetórias intelectuais: professoras do curso de ciências sociais da FFCL-USP (1934-1969). São Paulo, Humanitas, 2011.

UsP. Anuário da Faculdade de Filosofia, Ciências e Letras (1939-1949). São Paulo, v. II, 1953.

- Atas da Congregação da Faculdade de Filosofia Ciências e Letras. São Paulo, sessão 14 ago. 1968a.

. Atas do Conselho Técnico-Administrativo. São Paulo, sessão 18 abr.1968b.

WoOLF, Virginia. Profissões para mulheres. In: . Profissões para mulheres e outros artigos feministas. Porto Alegre, L\&PM, 2013 [1931], pp.9-19. (Coleção L\&PM POCKET, vol. 1032). 